\title{
INFORMAÇÃO E O PROFISSIONAL DA ÁREA DA MỦSEOLOGIA: UMA DISCUSSÃO EPISTEMOLÓGICA
}

\author{
INFORMACIÓN Y EL PROFESIONAL EN EL CAMPO \\ DE LA MUSEOLOGÍA: UN DEBATE EPISTEMOLÓGICO
}

\author{
Emanuela Souza Ribeiro*
}

\section{RESUMO:}

Introdução: Este trabalho analisa o lugar da informação no campo da Museologia, em suas relações interdisciplinares com a Ciência da Informação.

Objetivos: Analisar as relações epistemológicas entre a Museologia e a Ciência da Informação, tendo como eixo central a Documentação em Museus.

Metodologia: Como método de pesquisa utilizou-se a revisão de bibliografia, privilegiando-se as contribuições de Pinheiro (1999, 2012), Lima (2002) e Cerávolo e Tálamo (2000).

Resultados: $O$ conceito de informação assume um papel preponderante na construção das relações interdisciplinares, pois é a partir do seu uso que a Museologia se aproxima da Ciência da Informação, tanto nos estudos acadêmicos como na aplicação empírica e na prática profissional.

Conclusões: $O$ conceito de informação está na base da maior parte das relações interdisciplinares entre a Museologia e a Ciência da Informação e, especialmente no âmbito da Documentação em Museus, já vem ocorrendo relações interdisciplinares entre as áreas, sinalizando um panorama de contínuo crescimento entre essas relações, apesar da necessidade de maiores estudos sobre o tema.

Palavras-chave: Interdisciplinaridade. Informação. Museologia. Ciência da Informação.

*Doutora em História pela Universidade Federal de Pernambuco. Docente do curso de Museologias da Universidade Federal de Pernambuco. E-mail: emanuelasousaribeiro@yahoo.com.br 


\section{1 À GUISA DE INTRODUÇÃO: INFORMAÇÃO, CIÊNCIA DA INFORMAÇÃO E MUSEOLOGIA}

Discutir as relações entre a informação e o profissional da Museologia pode parecer uma tarefa simples, pois, mesmo para o senso comum, parece óbvio que a Museologia se relaciona fortemente com a transmissão de informações. Contudo, este é um debate que não pode ser esgotado em uma única abordagem e, em nosso ponto de vista, possui relações intrínsecas com questões epistemológicas da Museologia e da Ciência da Informação, bem como com a própria constituição destes campos e de suas matrizes disciplinares.

Um primeiro problema a ser enfrentado diz respeito ao próprio conceito de informação, palavra que, segundo Capurro e Hjorland (2007, p.155) costuma ser usada para designar dois tipos de atos: "o ato de moldar a mente e $o$ ato de comunicar conhecimento". Assim, os mesmos autores nos advertem que, na Ciência da Informação, o uso do termo "informação" deve ser sempre associado ao reconhecimento das necessidades de cada indivíduo ou comunidade:

Quando usamos o termo informação em $\mathrm{Cl}$, deveríamos ter sempre em mente que informação é o que é informativo para uma determinada pessoa. O que é informativo depende das necessidades interpretativas e habilidades do indivíduo (embora estas sejam frequentemente compartilhadas com membros de uma mesma comunidade de discurso) (CAPURRO e HJORLAND, 2007, p.154 -155)

Como neste trabalho o uso do termo informação está associado a duas disciplinas diferentes, torna-se necessário iniciar nossa argumentação fazendo uma distinção acerca do uso do termo tanto na Museologia como na Ciência da Informação. Nesta área o termo informação costuma ser usado como elemento definidor da própria identidade disciplinar, conforme, por exemplo, a delimitação adotada por Capurro e Hjorland para apontar o objeto dos profissionais da Ciência da Informação:

Acreditamos que o foco dos profissionais da informação (distintos dos outros grupos de profissionais a que estão 
servindo) implica uma abordagem sociológica e epistemológica para a geração, coleta, organização, interpretação, armazenamento, recuperação, disseminação, transformação e uso da informação (CAPURRO e HJORLAND, 2007, p.187).

Já para a Museologia, "a informação é o eixo central das ações museológicas" (BRUNO, 2011, p.171), ou seja, das ações dos museus e não necessariamente da Museologia enquanto disciplina. Tal distinção é extremamente importante, pois, nos ajuda a compreender a diferenciação entre a abordagem da informação feita pelos profissionais da Museologia e os da Ciência da Informação.

Para os teóricos da Museologia é ponto basilar a distinção entre o museu e a disciplina museológica. Assim, embora não seja o objeto central deste artigo, é importante apresentar uma breve discussão sobre o objeto de estudo da Museologia.

Ainda é muito comum encontrarmos publicações que definem a Museologia apenas a partir do museu. Este tipo de definição costuma traçar uma espécie de genealogia dos museus e apontar, para cada época, um perfil de museologia (ARAÚJO, 2012). De fato, não se pode dissociar a experiência histórica dos museus da constituição do campo da Museologia, contudo, este cenário se modificou profundamente, conforme explicam Soares, Carvalho e Cruz:

Uma separação disfuncional entre os agentes da prática e da teoria vêm caracterizando a museologia mundial desde o final da Segunda Guerra Mundial até os dias de hoje. [...] No Brasil, um campo mais ou menos homogêneo abarcando o contexto teórico e o prático de maneira ampla se criou a partir da profissionalização da Museologia, que, [...] se legitimou pela criação dos cursos de graduação junto a universidades e pelas leis de regulamentação da profissão (SOARES, CARVALHO e CRUZ, 2014, p.262).

Neste contexto, no último quartel do século $X X$, a definição do objeto de estudo da Museologia deslocou-se, ou melhor dizendo, alargou-se progressivamente, saindo do âmbito do museu para o da sociedade, conforme explica Guarnieri: "O objeto da museologia é o fato 'museal' ou fato museológico. O fato museológico é a relação profunda entre o homem - sujeito 
conhecedor -, e o objeto, parte da realidade sobre a qual o homem igualmente atua e pode agir" (GUARNIERI, 2010, p. 123).

A definição do objeto da museologia como o "fato museal" não é aceita integralmente na área, contudo, é integralmente aceita a perspectiva de que a museologia abrange mais do que apenas a instituição museu.

O alargamento dos objetos, e objetivos, da disciplina abrange, na opinião de alguns teóricos, o âmbito das relações humanas com a realidade, conforme explica Sheiner, para quem a Museologia é:

O campo do conhecimento dedicado ao estudo e análise do Museu enquanto representação da sociedade humana, no tempo e no espaço. Abrange o estudo das múltiplas relações existentes entre o humano e o Real, representadas sob diferentes formas de museus: museus tradicionais, baseados no objeto; museus de território, relacionados ao patrimônio material e imaterial das sociedades do passado e do presente; museus da natureza; museus virtuais/digitais (SHEINER, 2012, p.18).

De qualquer maneira, ambas as abordagens implicam em compreender que o museu e a Museologia se distinguem, o que, por sua vez, implica em perceber que a informação se faz presente de maneira distinta na Museologia e nos museus - uma vez que estes campos não se sobrepõem completamente.

Quando tratamos das áreas da Museologia, podemos dizer que existe uma "Museologia Aplicada" que abarca as atividades de Salvaguarda (incluindo a Documentação e a Conservação) e de Comunicação (que inclui a Expografia e a Ação educativo-cultural). Estas atividades, por sua vez, devem se relacionar através das atividades de Planejamento e Avaliação (CANDIDO, 2013, p. 20).

Estas áreas, no seu viés aplicado, costumam proporcionar uma maior interação entre a Museologia e os museus, sendo aquelas que mais apresentam sobreposições.

\footnotetext{
${ }^{1}$ Candido adota como delimitação geral a estruturação da Museologia nas seguintes áreas: Museologia Geral (inclui Teoria Museológica, História dos Museus, Administração de Museus), Museologia Especial (inclui os diversos textos e contextos museológicos), e Museologia Aplicada, que explicamos acima (CANDIDO, 2013, p. 20).
} 
Assim, trataremos a seguir de duas questões diversas: as relações disciplinares entre a informação, o museu e a Ciência da Informação e, por fim, do lugar da informação na Museologia.

Para tratar deste assunto, circunscreveremos nossa análise no âmbito da Documentação em Museus $^{2}$, tema que elegemos por relevância temática para análise das relações entre informação e museologia, e também por conveniência de aproximação pessoal com o tema.

Concluímos esta introdução ressalvando que esta temática é muito abrangente para ser esgotada no âmbito de um artigo, de maneira que este pretende apenas abrir portas para novos debates sobre a questão.

\section{INFORMAÇÃO, MUSEU E CIÊNCIA DA INFORMAÇÃO}

Ao tratar da informação no museu devemos retomar a já citada afirmação de Bruno: "a informação é o eixo central das ações museológicas" (BRUNO, 2011, p.171), ou seja, muito do que faz o museu está relacionado à informação, conforme segue explicando a autora:

Entende-se que os museus elaboram novas informações com base no estudo de seus acervos, desenvolvem distintos procedimentos técnicos para a preservação, salvaguarda e comunicação dos suportes da informação e, partindo de sua historicidade, geram novos indicadores documentais que, por sua vez, também se constituem em meios de informação (BRUNO, 2011, p.171).

Para contextualizarmos a explicação proposta por Bruno, é necessário compreender que o próprio conceito de museu abrange um grande conjunto de

\footnotetext{
2 Ao longo do texto faremos uso da expressão "Documentação em Museus", conforme a definição apresentada por CARVALHO e SCHEINER (2014), para quem o termo tradicional documentação museológica - seria impreciso, pois "A partir do entendimento que a Museologia tem trajetória, fundamentos e características distintas de seu objeto de estudo (independente da percepção que se tenha desse), é possível diferenciar documentação museológica de documentação em museus" (CARVALHO e SCHEINER, 2014, p. 16). É importante, porém, atentar para o fato de que na maior parte da bibliografia sobre o assunto, os autores utilizam o termo documentação museológica, que é a forma como se construiu a expressão ao longo do século $\mathrm{XX}$, até mesmo por questões de tradução.
} 
atividades, com finalidade social, de acordo com o estabelecido na Lei 11.904/2009, que regula as práticas museais no Brasil ${ }^{3}$ :

Art. 1ํㅡㄴ Consideram-se museus, para os efeitos desta Lei, as instituições sem fins lucrativos que conservam, investigam, comunicam, interpretam e expõem, para fins de preservação, estudo, pesquisa, educação, contemplação e turismo, conjuntos e coleções de valor histórico, artístico, científico, técnico ou de qualquer outra natureza cultural, abertas ao público, a serviço da sociedade e de seu desenvolvimento (BRASIL, 2009)

Se associarmos a definição de museu à definição de informação proposta por Capurro e Hjorland, não teríamos nenhum problema para afirmar que o museu faz: "geração, coleta, organização, interpretação, armazenamento, recuperação, disseminação, transformação e uso da informação" (CAPURRO e HJORLAND, 2007, p.187).

Em todas as suas atividades o museu atua com informação e, na Ciência da Informação o museu muitas vezes é compreendido como uma "unidade de informação que trabalha com a organização, o tratamento, o armazenamento, a recuperação e a disseminação da informação produzida a partir de suas coleções" (YASSUDA, 2009, p. 15).

Contudo, apesar de a informação estar presente em todas as áreas dos museus, podemos afirmar que no dia-a-dia da "museologia real"4, nem sempre é assim que a instituição compreende - o que é perfeitamente inteligível se atentarmos para o fato de que se trata de instituições cuja atuação cotidiana nem sempre está relacionada com o campo acadêmico e nem mesmo com os museólogos - e muito menos com os cientistas da informação.

A diferenciação de tarefas (do ponto de vista administrativo) entre as áreas da instituição é determinante no sentido de atribuir a discussão sobre a

\footnotetext{
${ }^{3}$ A definição de museu presente na legislação brasileira é muito semelhante à versão atual da definição proposta pelo Conselho Internacional de Museus (ICOM), instituição criada em 1946.

${ }^{4}$ A expressão "museologia real" é citada por CANDIDO (2013, p. 23-24), retomando argumentos de Waldisa Russio e Cristina Bruno, para se referir às condições vividas no cotidiano das instituições museais e dos meios de comunicação de massa, por oposição à museologia ensinada e sonhada nos cursos de Museologia e nas reflexões teóricas do campo.
} 
informação às áreas que tratam da Documentação em Museus ${ }^{5}$ que, conforme LIMA (2008) trata de:

[...] "muitas atividades: processo de entrada e registro, documentação legal, catalogação, controle de movimento [gerenciamento de acervo] e mais...", (KIELGAST, HUBBARD, 1997, p. 274) compreende: a elaboração da informação voltada ao conhecimento do acervo (objeto/exemplar/espécime/ território e, também, o registro da manifestação cultural intangível); o seu manejo à disseminação dos conhecimentos que lhes são pertinentes, em ambiente interno e externo ao museu, em qualquer circunstância pela qual passam as coleções agregando informação à sua existência museológica (LIMA, 2008, p. 8)

Desde muito cedo, na trajetória das instituições museais, o ICOM preocupou-se com o estabelecimento de padrões para a documentação das coleções dos museus. Já na década de 1950 foi criado, no âmbito do ICOM, o Comitê Internacional para a Documentação (CIDOC), que atuou progressivamente no estabelecimento de padrões e políticas para a documentação dos museus. Conforme explicam Cerávolo e Tálamo (2000, p. 242), ao longo dos anos 1960,

- CIDOC tratou de questões relativas a padrões para o registro de museus, como também da compatibilidade entre eles [...]. A partir de 1967, ainda este organismo defrontou-se com discussões embrionárias sobre 0 uso de técnicas informatizadas. Contudo, o maior empenho dirige-se para a configuração básica dos chamados 'sistemas de documentação', que serão difundidos nos anos 80, quando florescem propostas de sistemas dessa natureza (CERÁVOLO e TÁLAMO, 2000, p. 242).

Destacamos uma intensa atuação internacional do CIDOC que, apesar das inúmeras dificuldades, pôde difundir, no âmbito dos museus e da Museologia, um conjunto de orientações técnicas básicas para as atividades de documentação.

\footnotetext{
${ }^{5}$ Certamente podemos identificar outras disciplinas da Museologia Aplicada que se relacionam com a informação, em especial aquelas vinculadas à Comunicação em Museus, que compreendem a expografia - relativa à montagem de exposições - e as atividades de educativo, áreas que, em geral, são as partes mais visíveis da atuação dos museus. Contudo, optamos por fazer o recorte de análise a partir da documentação em museus
} 
A ação do CIDOC é apontada por Lima (2008), como uma das performances institucionais que aproximaram museus, bibliotecas e arquivos:

Entre os resultados das ações dos GTs CIDOC apoiando comunidades museológicas em contexto informacional (conjugando Bibliotecas, Arquivos, Centros de Documentação/Informação) merecem ser citados os que abordam Documentação Museológica - acervos de diferentes características e perspectivas (LIMA, 2008, p.10).

Ou seja, no âmbito do processamento técnico da documentação nos museus, pode-se mapear uma trajetória de integração dos museus com outras instituições que lidam com a informação a partir do CIDOC. Esta integração não ocorreu por acaso, pois, fazem parte do CIDOC, no âmbito internacional, profissionais de diversas áreas, desde documentalistas, a arquivistas e cientistas da informação. Lima $(2008$, p. 8) nos informa que, entre os membros do Comitê destacaram-se profissionais na informação, inclusive membros da Association for Information Science and Technology (ASIS\&T).

De acordo com a definição de Lima (2008), amparada em Pinheiro (1999), neste âmbito dos museus, as relações com a Ciência da Informação e o uso do conceito de informação - se dão através de aplicações práticas. As autoras apontam que "a Museologia constitui área de aplicação da Ciência da Informação" (LIMA, 2008, p. 5), o que não exclui a possibilidade de que ocorram relações interdisciplinares neste âmbito, sendo que estas "atuam em nível de projetos operacionais" (LIMA, 2008, p. 5).

A seguir trataremos das relações entre a informação, a Ciência da Informação e a Museologia, no âmbito disciplinar, de maneira a discutirmos algumas questões acerca de outras formas possíveis de relação interdisciplinar.

\section{INTERDISCIPLINARIDADE, INFORMAÇÃO, MUSEOLOGIA E A CIÊNCIA DA INFORMAÇÃO}

Ao apresentarmos, na introdução, algumas definições acerca do objeto da disciplina Museologia, certamente já deixamos clara nossa posição, acerca do lugar epistemológico da disciplina frente à Ciência da Informação. 
Embora para alguns autores a Museologia seja parte dos eixos disciplinares que formam a Ciência da Informação, esta opinião não é partilhada pela Museologia, conforme explica Lima (2008) ao se referir ao resultado de extensa revisão de bibliografia publicada até o final da década de 1980, sobre as relações entre ambas disciplinas:

Todos convergem para reconhecer o relacionamento entre as duas disciplinas e, embora não se coloque sob o foco da discussão a metodologia empregada para os resultados por eles obtidos, no entanto, deve-se mencionar a inserção da Museologia (Wersig e Nevelling; Yuexiao) em grupo nomeado Ciências da Informação -- postura que, ainda, não encontra concordância no domínio da Museologia, visto que aceitar a proposição poderia interferir na sua identidade e espaço que, arduamente, estão sendo conquistados no universo do conhecimento (LIMA, 2008, p. 5)

Além de não ser partilhada pelos autores da Museologia, nos dias atuais não há - salvo melhor juízo - defesa explícita desta posição em textos acadêmicos.

Além dos autores citados por Lima, outra interpretação bastante comum neste sentido surgiu a partir de leituras apressadas do argumento das "3 Marias", defendido por Smit (1993), cujo texto - já clássico - na realidade se refere às relações disciplinares entre a Museologia, a Arquivologia e a Biblioteconomia e a documentação no âmbito dos documentos audiovisuais.

A autora se ampara em Homulus (1990 apud SMIT, 1993, p. 81) para argumentar em favor da aproximação disciplinar no aspecto da coleta e guarda de cultura pelas instituições (museu, arquivo e biblioteca), para, a seguir, desenvolver sua própria argumentação acerca do tema, enfatizando a proximidade disciplinar a partir do viés do conceito de documento (SMIT, 2008).

Para Smit, amparada em extensa revisão de bibliografia, o conceito de documento está associado à "evidência que faz com que outros o percebam como documento, ressaltando o caráter relativo da caracterização" (SMIT, 2008, p. 15). Contudo, ao tratar de documentação, a autora busca suas origens na Biblioteconomia, tratando-a como uma dissidência desta, e considerando-a uma precursora da Ciência da Informação (SMIT, 2008, p. 19), não apontando nenhuma relação mais direta com a Museologia. 
Mesmo autores que são enfáticos em defender uma maior aproximação entre a Museologia e a Ciência da Informação (ARAÚJO, 2014, ARAÚJO e TANUS, 2012), são explícitos em afirmar que ao realçar as convergências entre a Museologia, a Biblioteconomia, a Arquivologia e a Ciência da Informação, buscam apontar as áreas de contato, e não defender a fusão destas disciplinas no escopo da Ciência da Informação (ARAÚJJ, 2014, p. 158).

Araújo e Tanus apontam como áreas principais de convergência: as instituições - também se baseando no argumento de Homulus, já citado -, o conceito de documento - assim como Smit -, o estudo da memória enquanto informação, e o tronco de formação profissional que se desenvolveu em algumas universidades do país nos últimos anos (ARAÚJO e TANUS, 2012).

É ainda Araújo que desfaz o equívoco relativo à afirmação de que a Ciência da Informação deveria ser o tronco comum da Museologia, da Biblioteconomia, e da Arquivologia:

Ela [a afirmação] também mostra-se inadequada: as três áreas não surgem da ciência da informação, na verdade são até anteriores a ela. Também o argumento de que a ciência da informação deveria ser o 'guarda-chuva' das três não se sustenta: uma parte imensa destas áreas (sobretudo da museologia) encontra-se além da dimensão informacional que as envolve, o que significa que o estoque de conhecimento de cada uma não cabe no escopo da ciência da informação (ARAÚJO, 2014, p. 158)

Assim, podemos perceber que no âmbito da literatura acadêmica esta é uma questão pacificada nos dias atuais, quando todas as disciplinas referidas buscam fortalecer sua identidade e, ao mesmo tempo, compreender suas relações interdisciplinares ${ }^{6}$.

Neste sentido, fazemos referência à extensa produção de Pinheiro (1999, 2008, 2012) sobre as relações interdisciplinares da Ciência da

${ }^{6}$ Certamente temos ciência de que no âmbito das políticas institucionais universitárias a questão não está pacificada, em especial no contexto dos cursos de graduação em Museologia que fazem parte de Departamentos ou Escolas de Ciência da Informação. Contudo, essa problemática não tem natureza epistemológica, de modo que não será tratada neste trabalho. 
Informação com a Museologia e, consequentemente, com o lugar da informação neste contexto.

Antes de mais nada, convém explicitar o conceito de interdisciplinaridade apresentado pela autora, que se baseia em Japiassu e Marcondes para afirmar que se trata de um:

Método de pesquisa e de ensino suscetível de fazer com que duas ou mais disciplinas interajam entre si, esta interação podendo ir da simples comunicação das idéias até a integração mútua dos conceitos, da epistemologia, da terminologia, da metodologia, dos procedimentos, dos dados e da organização da pesquisa, ...nova etapa do desenvolvimento do conhecimento científico e de sua divisão epistemológica, e exigindo que as disciplinas científicas, em seu processo constante e desejável de interpenetração, fecundem-se cada vez mais reciprocamente. (JAPIASSU; MARCONDES, 1991, p.136 apud PINHEIRO, 2012, p. 11)

Em trabalho publicado ainda em 1999, Pinheiro apresentava as diversas áreas da Ciência da Informação e suas disciplinas afins (PINHEIRO, 1999). Neste trabalho a autora construiu um diagrama em que eram apontadas "as duas faces da Ciência da Informação, tecnológica e social, na sua universalidade, e certamente suas tendências nacionais e locais" (PINHEIRO, 1999, p. 174).

Neste diagrama estão elencados como áreas da Ciência da Informação: Automação, Comunicação científica e tecnológica; Biblioteconomia, Representação da Informação; Sistema de recuperação da informação; Estudos de usuários; Redes e sistemas de informação; Economia da informação; Divulgação científica; Epistemologia da Ciência da Informação; Informação, cultura e sociedade; Administração de sistemas de informação.

$\mathrm{E}$ destas áreas, seis estão relacionadas com a Museologia, dentre outras disciplinas, a saber: Automação, Administração de Sistemas de Informação, Informação, cultura e sociedade, Redes e sistemas da informação, Sistema de recuperação da informação e Representação da informação (PINHEIRO, 1999, p. 174). A estas áreas, tomamos a liberdade de acrescentar, dentre as citadas por Pinheiro, os Estudos de usuários e a Divulgação Científica, como áreas que têm se relacionado fortemente com os museus e a Museologia nos dias atuais. 
De acordo com a Pinheiro "há indícios de convergências teóricas entre Ciência da Informação e Museologia que se manifestam de diferentes formas: em abordagens, aplicações, aspectos técnicos ou operacionais, acadêmicos e tecnológicos" (PINHEIRO, 2012, p. 12). Em uma classificação mais geral, podemos dizer que são convergências "teóricas, empíricas e da prática profissional" (PINHEIRO, 2012, p. 12).

Nas três classificações apontadas pela autora (PINHEIRO, 2012), assim como nas áreas listadas acima (PINHEIRO, 1999) podemos perceber que o conceito de informação assume um papel preponderante na construção das relações interdisciplinares, pois é a partir do seu uso que a Museologia se aproxima da Ciência da Informação, tanto nos estudos acadêmicos como na aplicação empírica e na prática profissional.

Retomando as áreas citadas por Pinheiro (1999), percebe-se que é a informação que aproxima as áreas da Automação, Administração de Sistemas de Informação, Informação, cultura e sociedade, Redes e sistemas da informação, Sistema de recuperação da informação, Representação da informação, Estudos de usuários e Divulgação Científica.

$\mathrm{Na}$ Museologia, assim como nos museus, estas áreas estão vinculadas às temáticas relativas à documentação, e são estudadas, com maior aprofundamento, nas disciplinas vinculadas à Documentação em Museus ${ }^{7}$.

O uso do termo 'documentação' nos remete imediatamente às discussões propostas por Smit (2008) e, de fato, faz-se necessário definir o que é o documento no museu e na Museologia, discussão para a qual Smith contribui ao definir o conceito e as características do documento em geral. Contudo, para a Museologia, o reconhecimento de algo como documento passa necessariamente, por um processo de atribuição de valor específico, o processo de musealização, definido por Loureiro como:

\footnotetext{
${ }^{7}$ Certamente também há relações importantes com as áreas da Museologia vinculadas à Comunicação em museus, assim como nas atividades que fazem a interrelação entre a Salvaguarda e a Comunicação, em especial a Avaliação.
} 
[...] conjunto de ações caracterizadas pela separação/deslocamento do contexto original e privação das funções de uso de alguns objetos, que passariam a desempenhar a função de documentos. Utilizamos, neste estudo, a expressão 'objeto musealizado' para ressaltar o caráter de processo presente nas práticas que envolvem a musealização. (LOUREIRO, 2007, p. 8).

Ou seja, quando falamos da Documentação em Museus, estamos nos referindo a uma disciplina da Museologia que estuda a informação através de documentos aos quais já foi (ou está sendo) atribuído valor cultural característico do museu e do patrimônio cultural.

Neste sentido, a informação que se estuda já é selecionada a partir da ótica disciplinar, mesmo quando se está estudando a informação acerca da vida dos objetos antes da musealização. Trata-se, deste modo, de estudar a informação construída a partir da Museologia e não da Ciência da Informação.

Por outro lado, alguns conceitos da Ciência da Informação vêm fecundando o campo da Documentação em Museus já há algumas décadas, tanto no que diz respeito à organização da informação, quanto no que tange à recuperação da informação.

Podemos fazer referência a um movimento de aproximação que vem acontecendo desde a década de 1980, pois, este período, no Brasil, foi muito profícuo no que tange às discussões sobre a documentação em museus, seja por conta de diversos estudos publicados sobre a área ${ }^{8}$, seja por conta de programas institucionais de documentação de bens culturais ${ }^{9}$ e, também, pela atuação do CIDOC no Brasil, conforme já apontado anteriormente, em especial com a disseminação do conceito de sistemas de documentação (CERÁVOLO e TÁLAMO, 2000, p. 242).

\footnotetext{
${ }^{8}$ Podemos nos referir aos trabalhos de controle de vocabulário (FERREZ e BIANCHINI, 1987), bem como a trabalhos de sistematização de rotinas (CAMARGO MORO, 1986).

${ }^{9} \mathrm{O}$ trabalho pioneiro do Museu Nacional de Belas Artes, que desenvolveu o Projeto SIMBA Sistema de Informação do Acervo do Museu Nacional de Belas Artes, iniciou-se na década de 1980, alcançando resultados de informatização apenas na década seguinte (GEMENTE, ABREU e FERREZ, 2004).
} 
Assim, nos remetemos ao conceito de "sistemas de informação", já defendido para aplicação na Museologia desde a década de 1980 por FERREZ e BIANCHINI (apud PINHEIRO, 2012, p. 14 -15), conforme explica Pinheiro:

É importante introduzir o pensamento de Ferrez e Bianchini (1987), inovador na época, para as quais o museu é um sistema de informação e os acervos museológicos constituem fontes de informação. A ideia, não incorporada às ações de museus há 20 anos, no Brasil e mesmo no exterior, hoje contribui para o reconhecimento da interdisciplinaridade entre Ciência da Informação e Museologia. É oportuno destacar que a primeira autora, Ferrez, é mestre em Ciência da Informação e os seus conhecimentos nessa área propiciaram tal visão (PINHEIRO, 20120, p. 14-15)

Mesmo que na prática dos museus esta concepção não tenha sido incorporada, como vimos anteriormente, no âmbito disciplinar trata-se de uma posição praticamente hegemônica, que vem sendo estudada em suas diversas acepções desde então, mas que ainda se encontra longe de ter sido esgotada e demanda a contínua interação com a Ciência da Informação.

Por exemplo, Cerávolo e Tálamo escrevendo já nos anos 2000, e apresentando resultados de uma sólida revisão de bibliografia publicada até a década de 1990, chamam atenção para o fato de que a documentação e os sistemas de documentação museológica estão articulados em três eixos: "o administrativo (para o gerenciamento das coleções), o curatorial (da pesquisa) e o documental (identificativo dos objetos/coleções), sendo que cada um deles responde à necessidades informativas diferenciadas" (CERÁVOLO e TÁLAMO, 2000, p. 245).

Apesar desta constatação, e ainda baseadas na revisão bibliográfica, as autoras concluem que os sistemas de documentação museológica "operam na direção do controle das coleções, atuando preferencialmente sobre o eixo administrativo/gerencial. Tais sistemas não podem ser caracterizados como sistemas de informações documentárias" (CERÁVOLO e TÁLAMO, 2000, p. 247).

Assim, evidencia-se que muito ainda há por fazer no sentido de atuar no âmbito documental e da pesquisa, eixos em que a Museologia tem trabalhado 
pouco nas últimas décadas, ocupada, ainda com as necessidades de padronização do eixo administrativo gerencial.

Aliás, neste aspecto, é importante destacar que o período de desenvolvimento e disseminação dos padrões CIDOC para a Documentação em Museus coincidiu com o período de desenvolvimento disciplinar da própria Ciência da Informação, de maneira que, nos dias atuais, quando buscamos novas abordagens para o trabalho com a informação, já encontramos um conjunto de ferramentas significativas desenvolvidas pela Ciência da Informação, dentre as quais se destacam aquelas relativas à recuperação da informação e aos estudos de usuários.

Soma-se a este movimento disciplinar de desenvolvimento da Ciência da Informação, o aumento da demanda por estudos pós-graduados no âmbito da Museologia, pois, como se sabe, foram criados na última década, mais de uma dezena de novos cursos de graduação na área, enquanto que o crescimento das pós-graduações em Museologia não ocorreu na mesma velocidade ${ }^{10}$.

Assim, com o aumento do número de museólogos nos cursos de pósgraduação em Ciência da Informação, estes vêm produzindo trabalhos em que as ferramentas analíticas da Ciência da Informação são utilizadas para aprofundar os estudos da Documentação em Museus, atuando em uma relação interdisciplinar que Lima qualifica como "interação disciplinar", que "facultam o movimento de 'atravessamento' que remete ao aspecto do deslimite" entre as áreas, ou seja, rompem "o critério da divisão das áreas disciplinares" (LIMA, 2008, p. 5 e 2).

O mesmo movimento pode ser observado ao percebermos 0 crescimento exponencial do interesse dos cientistas da informação acerca das problemáticas suscitadas pela questão da informação nos museus.

\footnotetext{
${ }^{10}$ Atualmente o sistema de avaliação de cursos de graduação do Ministério da Educação aponta a existência de 17 cursos de graduação em funcionamento. O primeiro curso de pósgraduação em Museologia, no Brasil, surgiu apenas em 2006, através de convênio de cooperação entre a Escola de Museologia da UNIRIO e o Museu de Astronomia e Ciências afins. Nesta data foi criado o curso de Mestrado e em 2011 o curso de Doutorado. Atualmente existem outros quatro cursos de Mestrado classificados na CAPES na área da Museologia: dois mestrados acadêmicos em Museologia (USP e UFBA) e dois mestrados profissionais (UFPI e MAST).
} 
Embora não tenhamos identificado trabalhos de síntese sobre o assunto, podemos apontar os estudos de Vilan Filho e Café (2013) e Café (2012), sobre a produção e a comunicação de pesquisas na área da Museologia, os estudos já referenciados de Araújo (2014) e colaboradores (ARAÚJO e TANUS, 2012), o trabalho de Mendes (2013) sobre a concepção de museu proposta por Otlet e Neurath, bem como trabalhos de Sampaio e Oliveira (2013) e Gouveia Júnior e Santos (2012) sobre as relações entre a Ciência da Informação e a Museologia. Todos são trabalhos produzidos por não museólogos inseridos na Ciência da Informação, ou seja, as problemáticas dos museus e da Museologia começam, felizmente, a suscitar questões para as outras disciplinas, de maneira que começam a ser produzidos olhares e discussões que vêem o campo de fora para dentro - o que é, sempre, muito salutar!

\section{CONSIDERAÇÕES FINAIS}

A título de considerações finais lembramos que esta discussão poderia ter sido construída a partir de outros exemplos, que não o da Documentação em Museus, e mesmo, enfatizando outros tipos de referenciais analíticos como, por exemplo, os estudos bibliométricos.

Assim, ao tempo em que afirmamos que o conceito de informação, e o seu uso no âmbito dos museus e da Museologia, tem promovido uma aproximação epistemológica relevante entre esta disciplina e a Ciência da Informação, também apontamos a necessidade de novos estudos que nos ajudem a compreender, e sistematizar, outras áreas de aproximação, como, por exemplo, os estudos de público/estudos de usuários, ou a avaliação dos trabalhos de educativo e das próprias exposições. Há ainda muitas fronteiras/limites que precisam ser analisados e, em todos eles, a informação ocupa lugar de destaque, podendo-se, através destes estudos, encontrar novas áreas de fecundação recíproca.

Também já está na hora de serem realizados estudos no sentido de analisar a presença de temas relacionados aos museus e à Museologia nos programas de Ciência da Informação fora do Rio de Janeiro, que graças aos estudos de Pinheiro (2012), já tem sido mapeado, concluindo a autora que: 
Em nosso País, o foco interdisciplinar da Ciência da Informação e Museologia se origina no IBICT, com a geração de número significativo de dissertações e teses envolvendo Ciência da Informação e Museologia. A concentração de pesquisas nessa linha acontecem no Instituto, com a participação de pesquisadores em Museologia da UNIRIO presentes nos Grupos de Pesquisa do IBICT e da mesma forma e inversamente, pela presença de pesquisadores da Ciência da Informação do IBICT na UNIRIO, em uma verdadeira "fertilização cruzada" de ideias. Por outro lado, na UNIRIO, desde o final dos anos 1990 a preocupação com estudos interdisciplinaridade já se manifestava, sendo, portanto, um solo propício ao ensino e pesquisa interdisciplinar (PINHEIRO, 2012, p. 19)

Urge realizar este tipo de estudo nos estados em que foram criados os novos cursos de graduação em Museologia e que já possuíam programas de pós-graduação em Ciência da Informação. Certamente esse horizonte é diferente nas Universidades em que os cursos de graduação em Museologia estão situados em Departamentos de Ciência da Informação.

Há ainda muito o que pesquisar, pois, o reconhecimento e a sistematização destas zonas de encontro é fundamental para que as ações interdisciplinares sejam cada vez mais produtivas para ambas as áreas.

\section{REFERÊNCIAS}

ARAÚJO, C. A. A. Museologia: correntes teóricas e consolidação científica.

Museologia e Patrimônio. Rio de Janeiro, vol. 5 nํ2, p. 31 - 54, 2012. Disponível em:

$<$ http://revistamuseologiaepatrimonio.mast.br/index.php/ppgpmus/article/view/159/199 >. Acesso em: 25 jun. 2016.

\section{ARAÚJO, C. A. A. Arquivologia, Biblioteconomia, Museologia e Ciência da}

Informação: o diálogo possível. Brasília, DF: Briquet de Lemos, 2014.

ARAÚJO, C. A. A., TANUS, G. F. de S. C.. Proximidades conceituais entre Arquivologia, Biblioteconomia, Museologia e Ciência da Informação. Biblionline, João Pessoa, v. 8, n. 2, p. 27-36, 2012. Disponível em: $<$ http://www.ies.ufpb.br/ojs/index.php/biblio/article/view/14291/8635 >. Acesso em: 20 jul. 2016. 
BRASIL. Congresso Nacional. Lei no 11.904/2009, de 14 de janeiro de 2009. Institui o Estatuto dos Museus e dá outras providências. Diário Oficial da União. Poder Executivo, Brasília, DF, 14 jan. 2009. Disponível em: $<$ http://www.planalto.gov.br/ccivil 03/ Ato2007-2010/2009/Lei/L11904.htm> . Acesso em 25 jun. 2016.

BRUNO, M. C. O. Informações em museus: alguns argumentos e muitos desafios. In: SEMINÁRIO SERVIÇOS DE INFORMAÇÃO EM MUSEUS, 1., 2010, São Paulo, Anais... São Paulo: Pinacoteca do Estado, 2010.

CAFÉ, L. C. Os canais da comunidade científica de Museologia no Brasil: um estudo de referências em artigos de periódicos. Monografia (graduação) Universidade de Brasília; Faculdade de Ciência da Informação, 2012.

CAMARGO MORO, F. Museus: aquisição/documentação. Rio de Janeiro: Eça, 1986.

CANDIDO, M. M. D.. Gestão de Museus, diagnóstico museológico e planejamento: um desafio contemporâneo. Porto Alegre: Medianiz, 2013.

CAPURRO, R., HJORLAND, B. O conceito de informação. Perspectivas em Ciência da Informação. Belo Horizonte, v. 12, n. 1, p. 148 - 207, jan./abr. 2007. Disponível em: <http://bogliolo.eci.ufmg.br/downloads/CAPURRO.pdf> . Acesso em: 25 jun. 2016.

CARVALHO, L. M. e SCHEINER, T. Reflexões sobre museologia: documentação em museus ou museológica. In: ENCONTRO NACIONAL DE PESQUISA DA ANCIB, 15, 2014, Belo Horizonte: Anais ENANCIB... Belo Horizonte: Universidade Federal de Belo Horizonte - UFMG; ANCIB, 2014. Disponível em: $<$ http://enancib2014.eci.ufmg.br/documentos/anais/anais-gt9 > Acesso em: 25 jun. 2016.

CERAVOLO, S. M.; TÁLAMO, M.F. Tratamento e organização de informações documentárias em museus. Revista do Museu de Arqueologia e Etnologia. São Paulo, n. 10: p. 241-253, 2000.

FERREZ, H. D.; BIANCHINI, M. H. S. Thesaurus para acervos museológicos. Rio de Janeiro: Fundação Nacional Pró- Memória/Coordenadoria Geral de Acervos Museológicos, 1987.

GEMENTE, G.; ABREU, L.; FERREZ, H. D. Sistema de Informação do Acervo do Museu Nacional de Belas Artes (Simba): uma experiência em automação de museus. In: SEMINÁRIOS DE CAPACITAÇÃO MUSEOLÓGICA, 2004, Belo Horizonte: Anais... Belo Horizonte: Instituto Cultural Flávio Gutierrez, 2004.

GOUVEIA JÚNIOR, M., SANTOS, R. N. M. dos. Mudança de paradigma e sua ruptura: um estudo de caso na Museologia e a pluralidade paradigmática da Ciência da Informação. Transinformação, Campinas, v. 24, n.2, p. 117-126, maio/ago., 2012. Disponível em: <http://www.scielo.br/pdf/tinf/v24n2/a04v24n2.pdf>. Acesso em 20 jul. 2016.

GUARNIERI, W. R. C. A interdisciplinaridade em Museologia. In: BRUNO, M. C. O.

(Org.). Textos e contextos de uma trajetória profissional. São Paulo: Pinacoteca do Estado: Secretaria do Estado da Cultura: Comitê Brasileiro do ICOM, 2010. v. 1, p. 123 $-126$. 
LIMA, D. F. C.. Ciência da Informação e Museologia em tempo de conhecimento fronteiriço: aplicação ou interdisciplinaridade? ENCONTRO NACIONAL DE PESQUISA DA ANCIB, 9, 2008, São Paulo: Anais ENANCIB... São Paulo: Universidade de São Paulo - USP; ANCIB, 2008. Disponível em: $<$ http://enancib.ibict.br/index.php/enancib/ixenancib/paper/viewFile/2982/2108>. Acesso em: 20 jul. 2016.

LOUREIRO, Maria Lucia de Niemeyer Matheus. Fragmentos, modelos, imagens: processos de musealização nos domínios da ciência. DataGramaZero, v.8, n. 2, 2007, artigo 01.

MENDES, L. C.. Transformações na percepção do museu no contexto do movimento bibliográfico: as concepções de museu de Paul Otlet e Otto Neurath. Perspectivas em Ciência da Informação, v.18, n.4, p.185-199, out./dez. 2013. Acesso em: $<$ http://www.scielo.br/pdf/pci/v18n4/12.pdf>. Acesso em: 20 jul. 2016.

PINHEIRO, L. V. R.. Campo interdisciplinar da Ciência da Informação: fronteiras remotas e recentes. In: PINHEIRO, L. V. R. (Org.). Ciência da Informação, ciências sociais e interdisciplinaridade. Brasília; Rio de Janeiro: IBICT, 1999.

PINHEIRO, L. V. R.. Horizontes da informação em museus. In: GRANATO, M., SANTOS, C. P., LOUREIRO, M. L. N. M. (Org.). Documentação de museus. Rio de Janeiro: MAST, 2008, p. 79 - 102. (MAST Colloquia, 10)

PINHEIRO, L. V. R.. Confluências Interdisciplinares entre Ciência da Informação e Museologia. Museologia \& Interdisciplinaridade, vol.1, n.1, jan./jul. de 2012. Disponível em: <http://periodicos.unb.br/index.php/museologia/article/view/6840>. Acesso em 25 jun. 2016.

SAMPAIO, D. A., OLIVEIRA, B. M. J. F. de. Memória, museus e ciência da informação: uma perspectiva interdisciplinar. Biblios, n. 52, 2013. Disponível em:

$<$ http://biblios.pitt.edu/ojs/index.php/biblios/article/viewFile/121/174 >. Acesso em 20 jul. 2016.

SCHEINER, T. Repensando o museu integral: do conceito às práticas. Bol. Mus. Para. Emílio Goeldi. Cienc. Hum., Belém, v. 7, n. 1, p. 15-30, jan.-abr. 2012. Disponível em: < http://www.scielo.br/pdf/bgoeldi/v7n1/a03v7n1.pdf > Acesso em: 25 jun. 2016.

SMIT, J. W. A Documentação e suas abordagens. In: MUSEU DE ASTRONOMIA E CIÊNCIAS AFINS - MAST. Documentação em Museus. Rio de Janeiro: MAST, 2008, p. 11-22. (MAST Colloquia, 10)

SMIT, J. W. O documento audiovisual ou a proximidade das entre as 3 Marias. Revista Brasileira de Biblioteconomia e Documentação. São Paulo, v. 26, n. 1/2, p. $81-85$, jan./jun. 1993.

SOARES, B. B.; CARVALHO, L. M., CRUZ, H. V. O nascimento da Museologia: confluências e tendências do campo museológico no Brasil. In: MAGALHÃES, A. M.; BEZERRA, R. Z. 90 anos do Museu Histórico Nacional em debate (1922-2012). Rio de Janeiro: Museu Histórico Nacional, 2014, p.242-260. 
VILAN FILHO, J. L; CAFÉ, L. C.. A comunidade de Museologia no Brasil: aspectos da produção e dos canais de comunicação. ENCONTRO NACIONAL DE PESQUISA DA ANCIB, 14, 2013, Florianópolis: Anais ENANCIB... Florianópolis: Universidade Federal de Santa Catarina - UDSC; ANCIB, 2013. Disponível em: $<$ http://enancib.ibict.br/index.php/enancib/xivenancib/paper/viewFile/4342/3465>. Acesso em: 25 jun. 2016. YASSUDA, S. N. Documentação museológica: uma reflexão sobre o tratamento descritivo do objeto no Museu Paulista. Marília: 2009. Dissertação (Mestrado em Ciência da Informação) - Faculdade de Filosofia e Ciências, Universidade Estadual Paulista. Disponível em: <https://www.marilia.unesp.br/Home/PosGraduacao/Cienciadalnformacao/Dissertacoes/yassuda sn me mar.pdf>. Acesso em: 25 jun. 2016.

\title{
Title
}

Information and the museology professional: an epistemological discussion

\begin{abstract}
:
Introduction: This work analyzes the place of information in the Museology field, in its interdisciplinary relations with Information Science.

Objectives: Aims to analyze the epistemological relations between Museology and Information Science, having as central axis the Documentation in Museums.

Methodology: As a research method, the bibliography review was used, favouring the contributions of Pinheiro (1999, 2012), Lima (2002) and Cerávolo and Tálamo (2000).

Results: The concept of information plays a preponderant role in the construction of interdisciplinary relationships, since it is from its use that Museology approaches Information Science, both in academic studies and in empirical application and professional practice

Conclusions: The concept of information forms the basis of most of the interdisciplinary relationships between Museology and Information Science, and especially in the field of Documentation in Museums, interdisciplinary relations between areas have been occurring, indicating a panorama of continuous growth between these relations, despite the need for further studies on the subject.
\end{abstract}

Keywords: Interdisciplinarity. Information. Museology. Information Science.

\section{Titulo}

Información y el profesional en el campo de la museología: un debate epistemológico

\section{Resumen:}

Introducción: En este trabajo se examina el lugar de la información en el campo de la museologia, en sus relaciones interdisciplinares con la Ciencia de la Información.

Objetivos: Analizar la relación epistemológica entre Museología y Ciencias de la Información, con el eje central de la Documentación de Museos.

Metodología: Como método de investigación se utilizó la revisión de la literatura, privilegiando las contribuciones de Pinheiro (1999, 2012), Lima (2002) y Cerávolo y Tálamo (2000). 
Resultados: El concepto de información juega un papel importante en la construcción de las relaciones interdisciplinares, es de su uso de enfoques museología de las ciencias de la información, tanto en estudios académicos y aplicación empírica y práctica profesional

Conclusiones: El concepto de información es la base de la mayoría de las relaciones interdisciplinarias entre Museología y Ciencias de la Información, y especialmente la documentación de museos, se viene produciendo relaciones interdisciplinarias entre las dos áreas, lo que indica una visión general de crecimiento continuo entre estas, a pesar de la necesidad de realizar más estudios sobre el tema.

Palabras clave: Interdisciplinariedad. Información. Museología. Ciencias de la Información.

Recebido em: 25.08.2016

Aceito em: 30.11.2016 